\title{
A Calcium-Dependent Feedback Mechanism Participates in Shaping Single NMDA Miniature EPSCs
}

\author{
Masashi Umemiya, ${ }^{1}$ Nansheng Chen, ${ }^{2}$ Lynn A. Raymond, ${ }^{2}$ and Timothy H. Murphy ${ }^{2}$ \\ ${ }^{1}$ Department of Neurophysiology, Tohoku University School of Medicine, Sendai 980-8575, Japan, and ${ }^{2 K i n s m e n}$ \\ Laboratory Department of Physiology and Psychiatry, University of British Columbia, Vancouver, Canada V6T $1 Z 3$
}

NMDA receptors (NMDARs) are highly calcium-permeable and are negatively regulated by intracellular calcium during prolonged exposure to agonist. We have investigated whether calcium-mediated feedback occurs during transient exposure to glutamate during single synaptic events. Examination of miniature EPSCs (mEPSCs) indicated that the decay kinetics of the NMDAR component was markedly slowed by the intracellular perfusion of exogenous calcium buffers (BAPTA or Fluo-3). In contrast, the AMPA receptor component of the miniature EPSC was unaffected. Slow on-rate calcium buffers, such as EGTA, did not alter kinetics of the NMDAR component of the mEPSC. Addition of exogenous fast calcium buffers did not slow the decay kinetics of glutamate-evoked currents mediated by NR1/NR2A heteromers expressed in HEK 293 cells, suggesting that the effect we observed in neurons may be specific to processes associated with synaptically activated receptors. Trial-to-trial amplitude variability of miniature calcium transients mediated by NMDARs increased with the injection of exogenous calcium buffers, suggesting that the amplitude of synaptic calcium transients are maintained at a rather constant level by a calcium-mediated feedback mechanism.

Key words: NMDA receptors; calcium; NR2A; Fluo-3; glutamate receptor; development
Two classes of ionotropic receptors, NMDA-type and AMPAtype glutamate receptors (NMDARs and AMPARs, respectively) mediate most fast excitatory synaptic transmission in the CNS. Calcium influx through NMDARs plays a critical role in activity-dependent synaptic modulation, such as long-term potentiation (Collingridge and Bliss, 1995; Nicoll and Malenka, 1995; Malenka and Nicoll, 1999). Because NMDARs have high calcium permeability and are negatively regulated by intracellular calcium, the calcium-mediated inactivation of NMDARs could work as a negative feedback mechanism to regulate channel activity (Mayer et al., 1987; Vyklick'y et al., 1990; Jahr and Stevens, 1993; Rosenmund and Westbrook, 1993; Rosenmund et al., 1995; Tong et al., 1995; Ehlers et al., 1996; Jones and Westbrook, 1996). It has been shown that intracellular calcium levels affect several characteristics of NMDARs, including desensitization, rundown, and inactivation (Mayer et al., 1987; Vyklick'y et al., 1990; Jahr and Stevens, 1993; Rosenmund and Westbrook, 1993; Rosenmund et al., 1995; Tong et al., 1995; Ehlers et al., 1996; Jones and Westbrook, 1996; Krupp et al., 1996). Although evidence suggests that calcium-mediated feedback is at work during trains of synaptic stimuli (Rosenmund et al., 1995; Tong et al., 1995), it is not known whether a calcium-mediated feedback mechanism can control NMDAR activity within the time course of a single synaptic event (Vyklick'y et al., 1990; Jahr and Stevens, 1993;

\footnotetext{
Received July 11, 2000; revised Oct. 11, 2000; accepted Oct. 11, 2000.

M.U. is supported by the Ministry of Education, Science, Sports, and Culture of Japan. T.H.M. is supported by an operating grant from the Medical Research Council (MRC) of Canada and is an MRC Scientist. L.A.R. is supported by an operating grant from MRC (Canada). N.C. has a John Wasmuth Fellowship from the Hereditary Disease Foundation. We thank M. Senda, Dr. H. Sakagami, Dr. T. Kitamoto, and Dr. H. Yao of Tohoku University, and Dr. P. J. Mackenzie and Dr. S. Wang of the University of British Columbia.

Correspondence should be addressed to Masashi Umemiya, Department of Neurophysiology, Tohoku University School of Medicine, 2-1 Seiryo-cho Aoba-ku, Sendai 980-8575, Japan. E-mail: umemiya@mbc.sphere.ne.jp.

Copyright (C) 2001 Society for Neuroscience 0270-6474/01/210001-09\$15.00/0
}

Rosenmund and Westbrook, 1993; Rosenmund et al., 1995). To investigate factors that control synaptic responses mediated by NMDARs, we measured miniature EPSCs (mEPSCs) and $\left[\mathrm{Ca}^{2+}\right]_{\mathrm{i}}$ at single synapses by combining patch-clamp recording with imaging techniques (Murphy et al., 1994, 1995; Mackenzie et al., 1999; Umemiya et al., 1999). We have found that the injection of exogenous calcium buffers slowed the decay of the NMDAR component of mEPSCs. We suggest that calcium influx through NMDARs activates a calcium-mediated negative feedback mechanism to maintain the amplitude of calcium transients at a relatively constant level at single synapses.

\section{MATERIALS AND METHODS}

Primary cultures of neocortical neurons were prepared as described previously (Murphy et al., 1994, 1995; Umemiya et al., 1999). Briefly, neurons and glia were dissociated from 16-20 d gestation rat fetuses and were maintained at least 4 weeks in vitro, unless indicated otherwise. Neurons were viewed under an inverted microscope equipped with a $100 \times$ objective lens (Olympus, Hachioji, Japan). Recordings were made under voltage clamp using the whole-cell patch-clamp technique at room temperature. Whole-cell currents were filtered at $2 \mathrm{kHz}$, sampled at 5 $\mathrm{kHz}$, and stored on a personal computer using the pClamp system (Axon Instruments, Foster City, CA). The calcium-sensitive dye Fluo-3 (Molecular Probes, Eugene, OR) was included in the pipette solution at 0.5 $\mathrm{mM}$ unless indicated otherwise. The pipette solution contained (in $\mathrm{mM}$ ): $130 \mathrm{KMeSO}_{4}, 4 \mathrm{NaCl}, 20 \mathrm{HEPES}, 2 \mathrm{MgCl}_{2}, 3 \mathrm{MgATP}, 0.5$ Mag-fura-2, and 0.5 Fluo- $3, \mathrm{pH} 7.2$ by $\mathrm{KOH}$ (pipette resistance was $\sim 3 \mathrm{M} \Omega$ ). After the establishment of the whole-cell configuration, $\sim 10$ min was required to allow the dyes to fill the dendrites. We examined several sites to find synapses on the dendrites with a reasonable frequency of synaptic activity. The bathing solution for the recording contained (in $\mathrm{mm}$ ): $137 \mathrm{NaCl}$, $5 \mathrm{KCl}, 10 \mathrm{HEPES}, 4 \mathrm{CaCl}_{2}, 0.001 \mathrm{TTX}, 0.01$ glycine, and 0.01 bicuculline, pH 7.4 by $\mathrm{NaOH}$. In some experiments, we did not include glycine in the bathing solution. Supplementation of the medium with glycine did not lead to changes in the time course or amplitude of NMDA receptormediated mEPSCs (Umemiya et al., 1999), suggesting that these cultures contain adequate glycine to saturate NMDARs. In the measurement of calcium transients induced by voltage-gated calcium channels, $\mathrm{K}^{+}$in the pipette solution was substituted by $\mathrm{Cs}^{+}$to block potassium channels, and 
the bathing solution was the same as the standard recording solution, except that $4 \mathrm{mM} \mathrm{CaCl}_{2}$ was substituted by $2 \mathrm{mM} \mathrm{CaCl}_{2}$ and $2 \mathrm{mM} \mathrm{MgCl}_{2}$. The access resistance was $<20 \mathrm{M} \Omega$ and was monitored throughout each experiment.

Fluorescence images were recorded by an intensified CCD camera, the $\mathrm{XR}$ Gen III+ (Solamere, Salt Lake City, UT), at video rate (30 frames per second), captured on a personal computer using a video frame grabber, the PIXCI SV4 (EPIX, Buffalo Grove, IL), and stored to a hard disk. Excitation of Mag-fura-2, a low-affinity $\left[\mathrm{Ca}^{2+}\right]_{\mathrm{i}}$ probe, by $380 \mathrm{~nm}$ light enabled us to identify the dendrites and map their structure, because resting $\left[\mathrm{Ca}^{2+}\right]_{\mathrm{i}}$ in the absence of synaptic stimulation was typically low, resulting in little Fluo-3 fluorescence. Excitation of Fluo-3 by $490 / 25 \mathrm{~nm}$ light was used to measure the calcium transient. Recordings were terminated if the basal fluorescence level of Fluo-3 increased by $>10 \%$ of Mag-fura- 2 fluorescence. $\left[\mathrm{Ca}^{2+}\right]_{\mathrm{i}}$ was estimated from the ratio of Fluo-3 fluorescence normalized to Mag-fura-2 fluorescence $(\Delta F / F)$. A linear scaling of fluorescence changes to $\left[\mathrm{Ca}^{2+}\right]_{\mathrm{i}}$ is acceptable because of the high concentration of indicator used (see Results). To avoid photobleaching of calcium-sensitive dyes and cell damage, $15 \mathrm{sec}$ of optical recording was followed by at least a $15 \mathrm{sec}$ break. Analysis of baseline data indicated that little or no bleaching of Mag-fura-2 or Fluo-3 fluorescence occurred. After recording, neurons were voltage clamped to depolarized potentials to allow robust calcium influx to check the saturation level of calcium-sensitive dyes and the intensified CCD camera. In most cases, the largest calcium transients were below the saturation level of both dyes and the camera. Images and whole-cell currents were analyzed off-line using programs written by the IDL (Research System, Boulder, CO) and pClamp8 (Axon Instruments).

To measure calcium transients in the dendrite, we placed a five-pixelwide line on the dendrite (pixel size, $0.2 \times 0.2 \mu \mathrm{m}$ ). Pixel values across the line were averaged ( $1 \mu \mathrm{m}$ width) and stacked to create line scan-type images of calcium dynamics over time. Miniature synaptic calcium transients (MSCTs) were identified as calcium transients that were initiated from a point source and spread along the dendrite in both directions. MSCTs whose peaks occurred within a $1 \mu \mathrm{m}$ dendritic range were regarded as originating from the same synapse. The onset of MSCTs was identified as the first point that exceeded $1 \mathrm{SD}$ of the trace from the baseline. The amplitude of MSCTs was measured as the difference of the normalized fluorescence between the baseline and a maximum value of moving average of five consecutive points $(167 \mathrm{msec})$ within $500 \mathrm{msec}$ after the onset at the synapse. mEPSCs responsible for MSCTs were identified as mEPSCs that occurred within $33 \mathrm{msec}$ of the onset of an MSCT (Umemiya et al., 1999). The ANOVA test followed by Bonferroni's test for multiple comparisons and the paired $t$ test were used for statistical analysis. The mean and SEM are shown, unless otherwise mentioned.

Culture and transfection of HEK 293 cells (CRL 1573; American Type Culture Collection, Rockville, MD) were as described previously (Chen et al., 1999). Cells were passaged once every 2-4 d. For calcium phosphate transfection (Chen and Okayama, 1987), cells were plated at a density of $1 \times 10^{6}$ cells $/ \mathrm{ml}$ in $10 \mathrm{~cm}$ culture dishes (Falcon; Becton Dickinson, Franklin Lakes, NJ). Cells were transfected with cDNAs encoding NR1A [a gift from Dr. S. Nakanishi, Kyoto University, Kyoto, Japan; nomenclature of Sugihara et al., 1992; also known as NR1A-1a (Hollmann and Heinemann, 1994)] and $\epsilon 1$ (from mouse brain, also called NR2A, a gift from Dr. M. Mishina, University of Tokyo, Tokyo, Japan) at a ratio of $1: 1$. A total of $10 \mu \mathrm{g}$ of plasmid cDNA was used for transfection of a $10 \mathrm{~cm}$ culture plate. After transfection, $1 \mathrm{mM}(+)$-2-amino-5phosphonopentanoic acid (Research Biochemicals, Natick, MA) was added to the culture media, and the cells were transferred onto glass coverslips in $35 \mathrm{~mm}$ culture plates (Falcon). The whole-cell patch-clamp recording technique and recording solutions were essentially the same as described previously (Chen et al., 1999). Twenty-four to $36 \mathrm{hr}$ after the start of transfection, the cells were transferred to the recording chamber on the stage of an inverted microscope (Aviovert 100; Carl Zeiss, Thornburg, NY). Agonist-evoked currents were recorded in the wholecell mode under voltage clamp $\left(V_{\mathrm{H}}\right.$ of $\left.-60 \mathrm{mV}\right)$. Electrodes with open-tip resistances of 1-5 $\mathrm{M} \Omega$ were used. After establishing the whole-cell mode, cells were lifted from the coverslip. Ultrafast application of agonists was achieved by a piezo-driven $\theta$-tube (Hilgenburg, Malsfeld, Germany) (Chen et al., 1999). Control and agonist solutions were continuously gravity-fed through the two sides of the $\theta$-tube. Extracellular recording solution contained (in mM): $145 \mathrm{NaCl}, 5.4 \mathrm{KCl}, 1.8$ or $4.0 \mathrm{CaCl}_{2}, 11$ glucose, and 10 HEPES, titrated to $\mathrm{pH} 7.35$ with $\mathrm{NaOH}$. In all experiments, $50 \mu \mathrm{M}$ glycine was added to both control and glutamate- containing extracellular solutions. The intracellular recording solution contained (in $\mathrm{mM}$ ): $145 \mathrm{KCl}$, Fluo-3 (at indicated concentrations), 4 $\mathrm{MgATP}$, and $10 \mathrm{HEPES}$, titrated to $\mathrm{pH} 7.25$ with $\mathrm{KOH}$. Currents were sampled at $2 \mathrm{kHz}$ and acquired and analyzed using pClamp software and the Axopatch 200A amplifier (Axon Instruments). Current amplitude measurement and decay kinetics fitting were conducted with Clampfit software. The time constant for the NMDAR decay time course was determined by fitting the decay to a single exponential.

\section{RESULTS}

Using whole-cell patch-clamp recording techniques in combination with calcium imaging on primary cultures of cortical neurons, we have tested whether intracellular perfusion of fast calcium buffers alters the decay time course of NMDAR mEPSCs. We have used this approach because these buffers have been shown previously to inhibit other calcium-dependent processes of the receptor, such as inactivation (Vyklick'y et al., 1990; Lattanzio and Bartschat, 1991; Tong et al., 1995; Smith et al., 1996). To accomplish this, we recorded mEPSCs at various concentrations of the intracellular calcium buffer Fluo-3 in the presence of TTX and $0 \mathrm{Mg}^{2+}$ in the bathing solution (Fig. 1). We used Fluo-3 as a fast calcium buffer to permit comparison of our results with calcium imaging experiments. Although Fluo-3 has lower affinity for calcium than BAPTA, the forward binding rate of Fluo-3 for calcium is faster than that of BAPTA (Lattanzio and Bartschat, 1991; Naraghi and Neher, 1997).

To measure the decay time course of mEPSCs mediated by NMDARs, mEPSCs were aligned by their onset and averaged (for each neuron), and then the two temporal components (corresponding to AMPARs and NMDARs) were fitted to the sum of two exponential components (Bekkers and Stevens, 1989; Silver et al., 1992; Umemiya et al., 1999). We chose to study the dual AMPAR- and NMDAR-component mEPSCs and did not evaluate synapses with only slow components because calciumsensitive NR1/NR2A heteromers are preferentially distributed on "mature" synapses ( $\mathrm{Li}$ et al., 1998; Tovar and Westbrook, 1999). In addition, we used analysis of the fast AMPAR component to exclude mEPSCs that were distorted by electronic filtering of the dendrite. All of these measurements were made from cultures at 28-56 days in vitro (DIV). Our results indicate that the decay time constant of the NMDAR component of mEPSCs was dependent on Fluo-3 concentration (Fig. $1 A-D$ ). The decay time constant at $2 \mathrm{~mm}$ Fluo-3 (72.7 $\pm 4.4 \mathrm{msec} ; n=12)$ was significantly slower than that observed at $0.1 \mathrm{~mm}(26.5 \pm 1.9 \mathrm{msec} ; n=$ 10), $0.2 \mathrm{~mm}\left(31.8 \pm 1.8 \mathrm{msec} ; n=19 ; p<10^{-5}\right)$, and $0.5 \mathrm{~mm}$ $\left(48.5 \pm 1.7 \mathrm{msec} ; n=11 ; p<10^{-4}\right)$. The decay time constant at $0.1 \mathrm{~mm}$ was not significantly different from that at $0.2 \mathrm{~mm}(p>$ $0.05)$, suggesting that endogenous calcium buffers would dominate over Fluo-3 at these concentrations. To test this assumption, the decay time course of NMDAR-mediated mEPSCs were determined using perforated patch clamp (Amphotericin B; $29.2 \pm$ $2.3 \mathrm{msec}$ ) and were found to not be significantly different from the values obtained at 0.1 and $0.2 \mathrm{~mm}$ of Fluo-3 $(n=9 ; p>0.2)$. Data from perforated patch-clamp recordings indicate that endogenous buffering capacity of the neurons we have used is low enough to observe calcium-mediated facilitation of mEPSC decay. Experiments performed on cortical neurons in slices suggest that, in dendrites, $\sim 99 \%$ of calcium ions are bound to buffers (Helmchen et al., 1996). From this binding ratio, we estimate that the dendritic endogenous buffer capacity is $\sim 0.15 \mathrm{~mm}$. Therefore, relatively higher concentrations of exogenous buffers may be required to competitively block calcium-mediated feedback processes.

In contrast to the decay time constant, the amplitude of the 
A
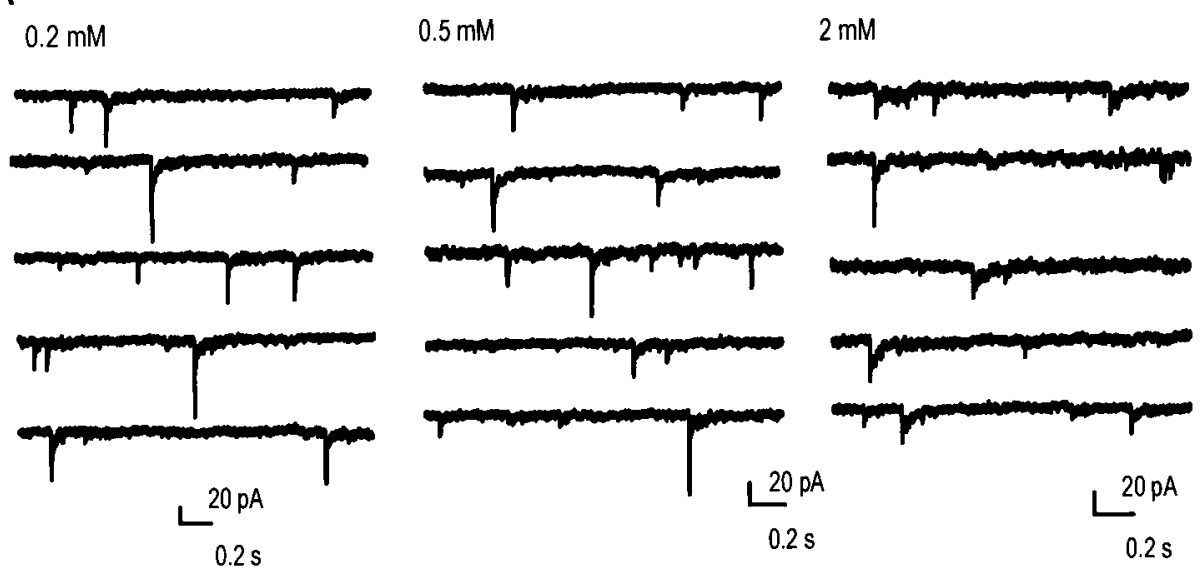

B
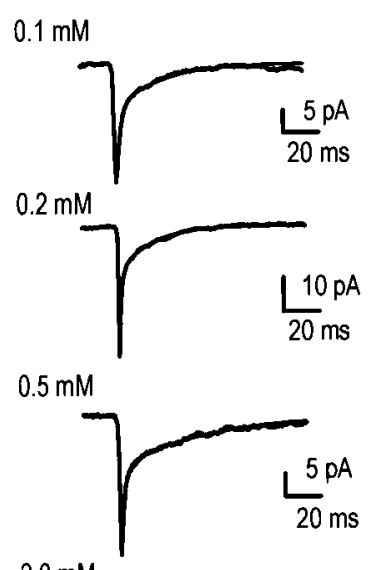

$2.0 \mathrm{mM}$

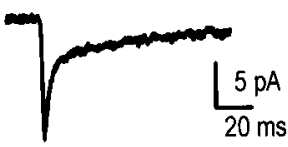

C

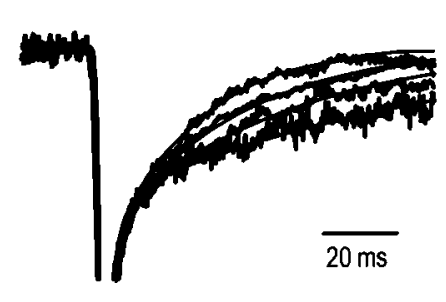

D

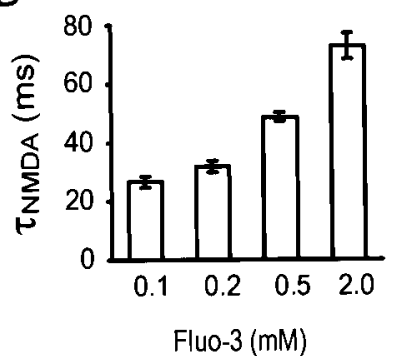

NMDAR component of mEPSCs was independent of the Fluo-3 concentration $(p>0.15)$ (Fig. $1 E)$. Because we have measured the amplitude of the NMDAR component of mEPSCs $9 \mathrm{msec}$ after the mEPSC peak, the contribution of AMPARs is negligible (Umemiya et al., 1999). The decay time constant of the fast (AMPAR) component was $<4 \mathrm{msec}(2.2 \pm 0.1 \mathrm{msec} ; n=62)$ (Silver et al., 1992; Bekkers and Stevens, 1996; Umemiya et al., 1999) and was independent of Fluo-3 concentration $(p>0.25)$ (Fig. 1A,E). The amplitude of the AMPAR component of the mEPSC was also independent of Fluo-3 concentration $(p>0.25)$ (Fig. 1E).

To confirm the effect of Fluo-3 on the decay time course of mEPSCs with a second $\mathrm{Ca}^{2+}$ chelator, we recorded mEPSCs with $0.5 \mathrm{~mm}$ BAPTA in the pipette solution. The decay time constant of mEPSCs mediated by NMDARs under these conditions was $54.7 \pm 2.3 \mathrm{msec}(n=4)$ and was not significantly different from that recorded with $0.5 \mathrm{~mm}$ Fluo-3 $(p>0.1)$. We also tested the effect of EGTA (a calcium buffer with a slow on-rate) on the decay time course of mEPSCs (Fig. 2), because it has been shown that EGTA is without effect on calcium-mediated inactivation of NMDARs (Vyklick'y et al., 1990; Lattanzio and Bartschat, 1991; Legendre et al., 1993; Tong et al., 1995; Krupp et al., 1996; Smith et al., 1996). The decay time constant of the

$\mathrm{E}$
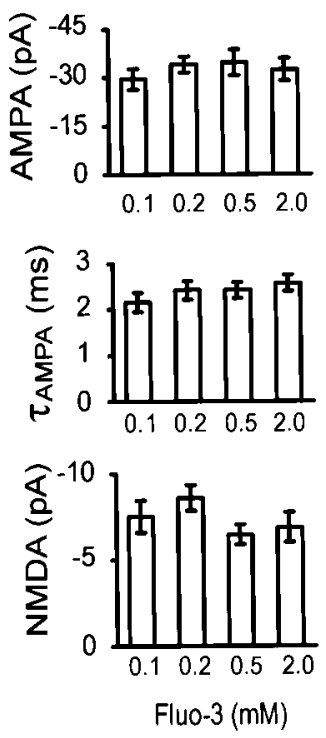

Figure 1. Effect of exogenous calcium buffers on the decay time course of mEPSCs mediated by NMDARs. $A$, Miniature EPSCs recorded with different concentrations of Fluo-3 in patch pipette solutions. $B$, Average mEPSCs with decay time courses fitted to the sum of two exponential components (thin line) are shown. The average traces were calculated from 250, 287, 94, and $76 \mathrm{mEPSC}$ for $0.1,0.2$, 0.5 , and $2 \mathrm{~mm}$ of Fluo-3, respectively. Decay time constants of slow components were 17,33, 47 , and $86 \mathrm{msec}$ for $0.1,0.2,0.5$, and $2 \mathrm{~mm}$ of Fluo-3, respectively. $C$, Normalized decay time course of slow components of mEPSCs shown in $B$. Traces are normalized to the amplitude at $10 \mathrm{msec}$ after the peak, in which the contribution of the AMPAR component is negligible. To better show the slow components, the fast peaks are truncated. $D, E$, Amplitude and decay time course of mEPSCs from pooled data. Numbers of neurons were 10, 19, 13, and 12 for $0.1,0.2,0.5$, and $2 \mathrm{~mm}$ Fluo-3, respectively.
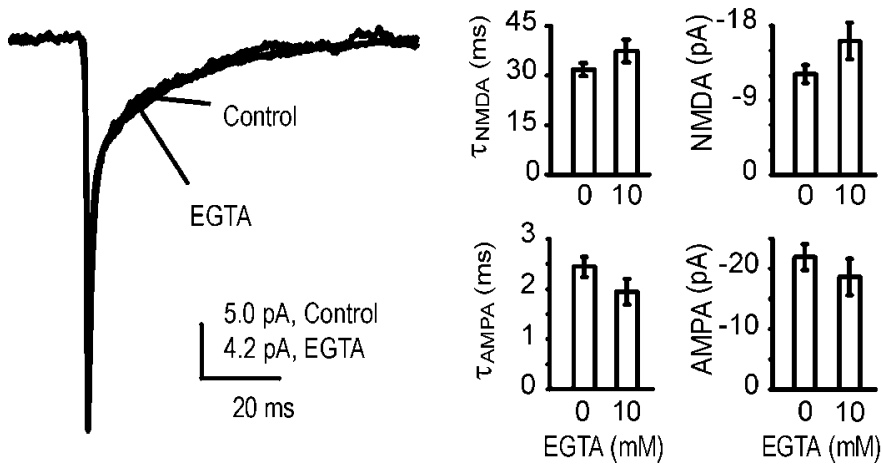

Figure 2. Decay time course of mEPSCs mediated by NMDARs is unchanged in the presence of EGTA. Decay time course of mEPSCs recorded with $0.2 \mathrm{~mm}$ Fluo-3 (Control) or $0.2 \mathrm{~mm}$ Fluo-3 and $10 \mathrm{~mm}$ EGTA. Average traces in the absence and presence of EGTA and decay time courses fitted to the sum of two exponential components are shown. Decay time constants of the slow NMDAR component are 33.2 and 27.2 msec in the absence and presence of EGTA, respectively. In the right panel, unpaired $t$ tests were used to assess differences in group data. Numbers of neurons were 6 and 16 with and without EGTA, respectively.

NMDAR component of mEPSCs was $36.2 \pm 3.9 \mathrm{msec}$ for recordings with $10 \mathrm{~mm}$ EGTA in addition to $0.2 \mathrm{~mm}$ Fluo-3 in the 

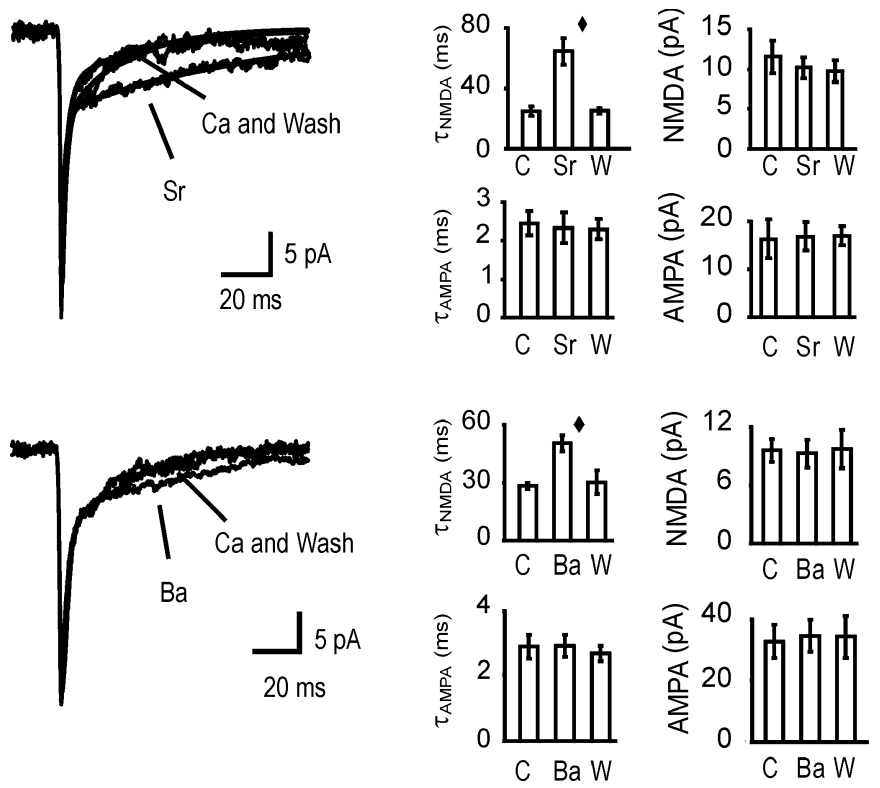

Figure 3. Effect of the substitution of calcium by barium and strontium on the decay of NMDAR mEPSCs. Decay time course of NMDA receptor-mediated mEPSCs recorded with $4 \mathrm{~mm}\left[\mathrm{Ca}^{2+}\right]_{\mathrm{O}}, 4 \mathrm{~mm}\left[\mathrm{Sr}^{2+}\right]_{\mathrm{O}}$, or $4 \mathrm{~mm}\left[\mathrm{Ba}^{2+}\right]_{\mathrm{O}}$. Records are superimposed for $\mathrm{Sr}^{2+}\left(\right.$ or $\left.\mathrm{Ba}^{2+}\right), \mathrm{Ca}^{2+}$, and a wash back to $\mathrm{Ca}^{2+}$ containing saline. In the right panel, pooled data from six neurons recorded with strontium and six neurons with barium are shown, and paired $t$ tests were used to assess differences. $p<0.005$.

pipette solution $(n=6)$. This value was not significantly different from that found for recordings with $0.2 \mathrm{~mm}$ Fluo-3 alone (31.8 msec; $p>0.2)$ but was faster than that found with $0.5 \mathrm{~mm}$ Fluo-3 (48.5 msec; $p<0.005)$. Also, EGTA was without effect on the average amplitude of NMDAR component of mEPSCs $(p>0.1)$ and on the decay time constant and the average amplitude of AMPAR components ( $p>0.2$ and $p>0.6$, respectively).

It has been shown that the calcium-mediated inactivation of NMDARs is suppressed by the substitution of calcium with other divalent cations (Legendre et al., 1993; Krupp et al., 1996). This is not surprising, because the inactivation of NMDARs can be mediated by calmodulin, which is highly calcium-specific (Ehlers et al., 1996; Zhang et al., 1998). Furthermore, non-calmodulindependent NMDAR inactivation is also relatively selective for calcium over barium and strontium (Krupp et al., 1996, 1999). To test the effect of other divalent cations, extracellular calcium was substituted with $4 \mathrm{~mm}$ strontium in recordings that included 0.2 mM Fluo-3 in the pipette solution (Fig. 3). The decay time constant of the NMDAR component of the mEPSC was $24.8 \pm$ $3.3 \mathrm{msec}$ in the bathing solution with calcium and was $64.7 \pm 8.8$ msec in the strontium-containing solution $(n=6 ; p<0.005$; paired $t$ test). A similar effect was observed with barium substitution $\left(n=6 ; p<10^{-3}\right)$. Substitution of $\mathrm{Ca}^{2+}$ with strontium or barium was selective in that it did not affect the amplitude of the NMDAR component $(p>0.2)$ or the amplitude and the decay time constant of the AMPAR component of the mEPSC $(p>0.4$ and $p>0.25$, respectively).

One possible pathway to mediate the facilitation of the decay of NMDAR-mediated mEPSCs is dephosphorylation of NMDARs by calcineurin (Tong et al., 1995). To test whether calcineurin mediates this effect, we added calcineurin inhibitors (200 nM cyclosporin A or $500 \mathrm{~nm}$ deltamethrin) with $0.1 \mathrm{~mm}$ of Fluo-3 in the patch pipette (Tong et al., 1995) (Fig. 4). In the presence of cyclosporin A or deltamethrin, the decay time constants of NMDAR-mediated mEPSCs were $58.1 \pm 5.6(n=6)$ and $52.5 \pm$ $8.3(n=5)$ msec, respectively; the decay constant was significantly slower than that measured at $0.1 \mathrm{~mm}$ of Fluo-3 alone $(p<0.001)$ but was not significantly different from that obtained at $0.5 \mathrm{~mm}$ of Fluo-3 $(p>0.15)$ and was still less than that observed with $2 \mathrm{~mm}$ Fluo-3. Our results suggest that dephosphorylation of NMDARs by calcineurin is, at least in part, responsible for the facilitation of the decay of NMDAR mEPSCs by calcium.

It has been shown that calcium-mediated inactivation is subunit-specific and that NR1/NR2A and NR1/NR2D heteromers are particularly sensitive to intracellular calcium (Krupp et al., 1996). In the forebrain, the expression of NR2B is high during the prenatal period, increases at birth, and reaches a plateau within 1 week, whereas the expression of NR2A is low in neonates and increases between 2 and 3 weeks after birth (Monyer et al., 1994; Sheng et al., 1994; Zhong et al., 1994; Li et al., 1998). The decay time course of mEPSCs also changes developmentally, because NR1/NR2B heteromers have slower kinetics than NR1/ NR2A heteromers (Carmignoto and Vicini, 1992; Hestrin, 1992; Chen et al., 1999; Tovar and Westbrook, 1999). To determine whether the decay time course of mEPSCs mediated by NR1/ NR2B heteromers was affected by calcium buffers, we measured the mEPSCs from cultures that were made from 16-17 d embryos and maintained for $<13$ DIV. At this developmental age, a larger proportion of the NMDAR component of mEPSCs appeared to be mediated by NR1/NR2B heteromers, because the decay time constant of the NMDAR component measured with $0.2 \mathrm{~mm}$ Fluo-3 was significantly $\left(p<10^{-6}\right)$ slower for these young cultures ( $<13$ DIV; see below) than that measured in older cultures $(>28$ DIV). Strikingly, we found that the decay time course of NMDARs in young cultures was independent of exogenous intracellular calcium buffers; the decay time constant was $88.0 \pm 15.0(n=5)$ and $80.0 \pm 8.5(n=7) \mathrm{msec}$, at 0.2 and $2 \mathrm{mM}$ of Fluo-3, respectively ( $p>0.3)$ (Fig. 5).

Because results obtained from older cultures appeared to be associated with predominantly NR1/NR2A-subtype synaptic receptors, we wanted to determine whether the effect of fast intracellular calcium buffers on the acceleration of NMDAR mEPSC decay was a property of the NR1/NR2A receptor itself. We tested this by expressing recombinant NR1/NR2A receptors in HEK 293 cells and recording the glutamate-evoked current under whole-cell voltage clamp (Fig. 6). Receptors were activated by short $(5 \mathrm{msec})$ pulses of glutamate $(1 \mathrm{~mm})$. In contrast to synaptically activated native receptors in neurons, we observed no significant difference in mEPSC decay time course when recordings with 0.2 and $2 \mathrm{~mm}$ Fluo- 3 were compared. The decay time constant of the fast component of the current (describes 83 and $85 \%$ of the amplitude for 0.1 and 2 mm Fluo-3, respectively) was similar to values obtained for mEPSCs mediated by native receptors in the presence of a relatively low concentration of calcium buffer. This result suggested that the calcium-dependent mEPSC decay process we observed in neurons is not an intrinsic property of the receptors and may be mediated by additional synaptically expressed protein components.

If calcium influx through NMDARs shapes the decay time course of mEPSCs mediated by NMDARs, rapid elevation of $\left[\mathrm{Ca}^{2+}\right]_{\mathrm{i}}$ by simultaneous opening of multiple channels within a synapse could facilitate the activation of the feedback mechanism (Imredy and Yue, 1992). To test the relationship between the initial amplitude of the NMDAR component of mEPSCs and the decay time course of mEPSCs at single synapses, we recorded 

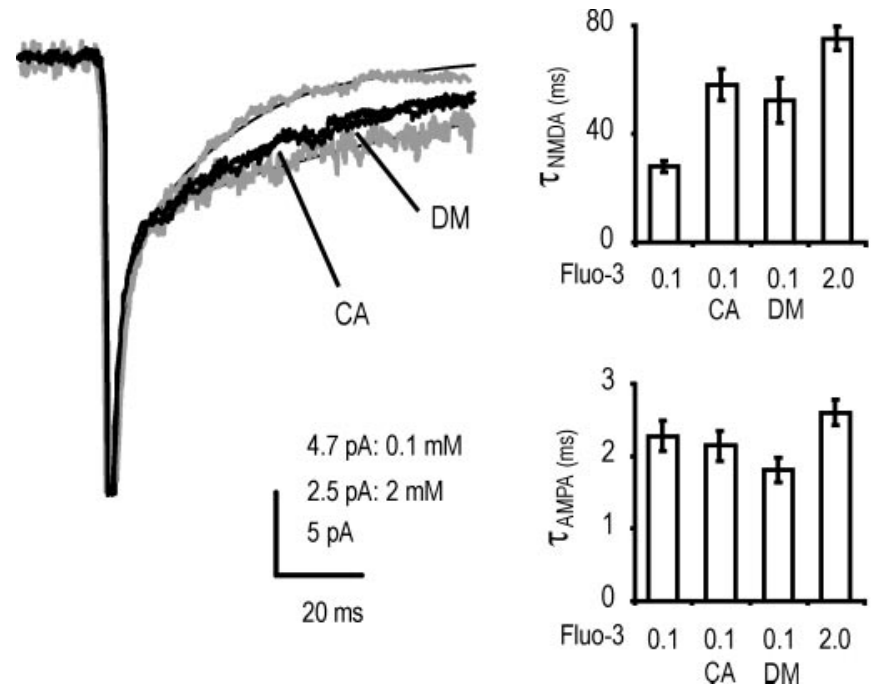

mEPSCs at identified synapses by simultaneous recording of whole-cell currents and $\left[\mathrm{Ca}^{2+}\right]_{\mathrm{i}}$ at the synapse using $0.2 \mathrm{~mm}$ Fluo-3 (Murphy et al., 1995; Umemiya et al., 1999) (Fig. 7). Previously, we have visualized local elevations in $\left[\mathrm{Ca}^{2+}\right]_{\mathrm{i}}$ in dendrites mediated by NMDARs activated by spontaneous quantal glutamate release termed MSCTs (Murphy et al., 1994, 1995; Mackenzie et al., 1999; Umemiya et al., 1999). Presumed synaptic sites were identified on the basis of the spatial and temporal profile of calcium transients: (1) earliest onset, (2) greatest rate of rise, and (3) largest amplitude. We assumed that multiple MSCTs occurring within a $1 \mu \mathrm{m}$ dendritic segment originated from a single synapse. Previous studies indicate that MSCTs observed under these conditions usually are mediated by the activation of NMDARs at single synapses (Murphy et al., 1994, 1995; Mackenzie et al., 1999; Umemiya et al., 1999; Wang et al., 1999). For synaptic current recordings, mEPSCs coincident with calcium transients at a synapse were recorded (Umemiya et al., 1999) (Fig. $7 A, B)$. To compare the decay time course of NMDAR mEPSCs with their initial amplitude, the amplitude of mEPSCs was measured between 7 and $12 \mathrm{msec}$ after the peak of the AMPAR
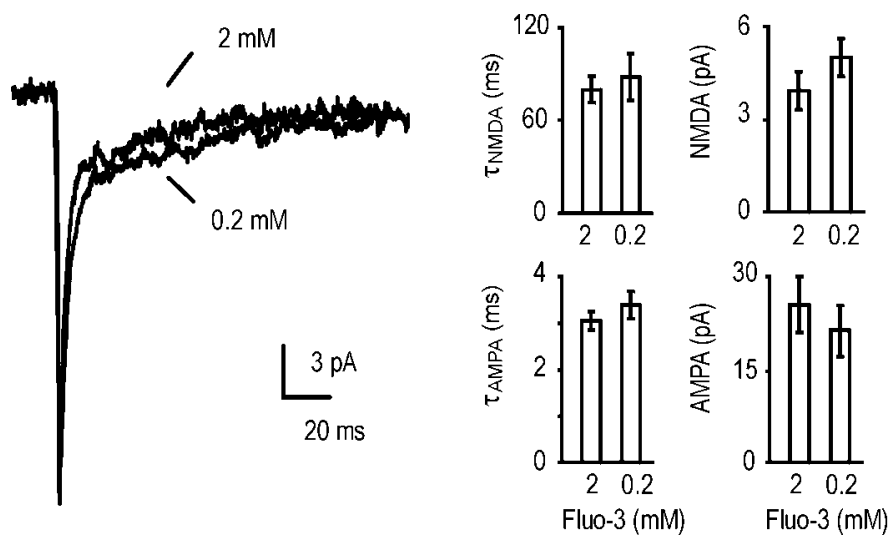

Figure 5. Decay time course of mEPSCs mediated by NMDARs in young cultures is insensitive to intracellular calcium buffer concentration. Average traces of mEPSCs recorded from young cultures ( $<13$ DIV) with 0.2 and $2 \mathrm{~mm}$ of Fluo-3 are shown. Decay time constants of the slow NMDAR component are 69.9 and $72.5 \mathrm{msec}$ for 0.2 and $2 \mathrm{~mm}$ Fluo-3, respectively. In the bottom panel, amplitude and decay time course of mEPSCs from pooled data. Numbers of neurons were five and seven for 0.2 and 2 mm Fluo-3, respectively.

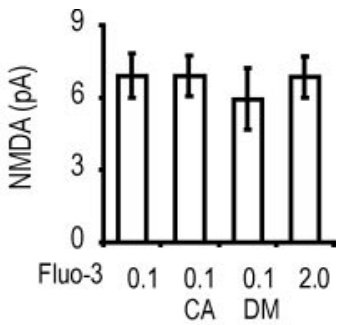

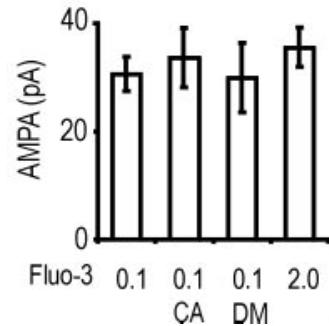

component. Next, the mEPSCs were sorted into two groups based on their initial NMDAR component amplitude, and two average traces were constructed from samples above and below the median amplitude (Fig. $7 C$ ). Each average trace was fitted to a sum of two exponential components, and the decay time constant of NMDAR components was determined. At six synapses on three cells, the decay time constant was faster for mEPSCs with larger initial NMDAR components than that observed for smaller mEPSCs (number of events per synapse, $8.7 \pm 1.2 ; p<0.05$; paired $t$ test) (Fig. 7D). On the other hand, the decay time constant of the AMPAR component of mEPSCs was independent of the NMDAR component initial amplitude $(p>0.7)$; decay time constants were $2.4 \pm 0.4$ and $2.4 \pm 0.4 \mathrm{msec}$ for small and large mEPSCs, respectively. We have also measured the relationship between the initial amplitude and decay time constants of NMDAR mEPSCs at $1 \mathrm{~mm}$ Fluo-3 (a buffer concentration that attenuates the feedback) and found that the decay time constants of large and small mEPSCs were not significantly different $(p>$ $0.25)$; decay time constants were $66.0 \pm 9.30$ and $62.2 \pm 11.5 \mathrm{msec}$ for small and large mEPSCs, respectively $(n=6)$. These data
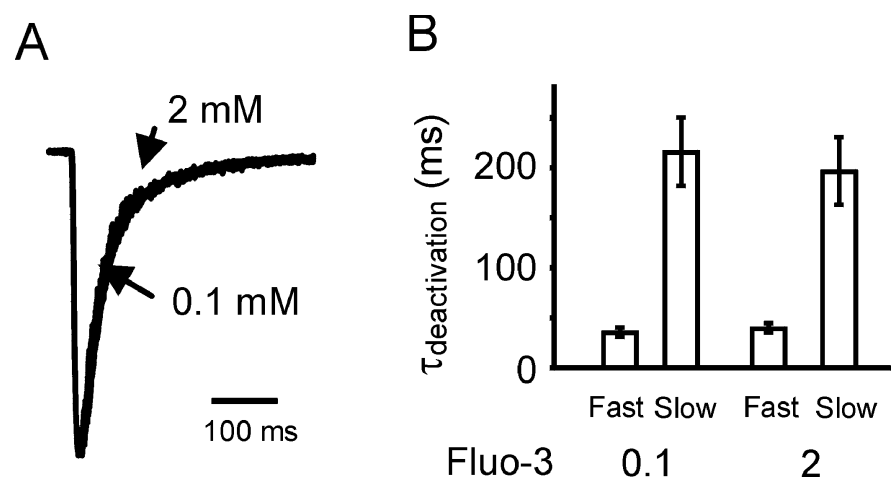

Figure 6. Decay of agonist-stimulated NR1A/NR2A-mediated currents expressed in HEK 293 cells. NR1/NR2A-type NMDARs expressed in HEK 293 cells were activated by $5 \mathrm{msec}$ pulses of $1 \mathrm{~mm}$ glutamate. Extracellular recording solution contained $4.0 \mathrm{mM} \mathrm{Ca}^{2+}$ and nominal 0 $\mathrm{Mg}^{2+}$. Left, Superimposed normalized records of NMDA receptormediated current in the presence of either 0.1 (black) or $2.1 \mathrm{~mm}$ Fluo-3 calcium buffer in intracellular recording solutions. Right, Average decay time courses for cells perfused intracellularly with $0.2(n=3$ cells $)$ or 2 ( $n=6$ cells) mm Fluo-3. No significant difference in decay $\tau$ was observed $(p>0.05)$. 
A

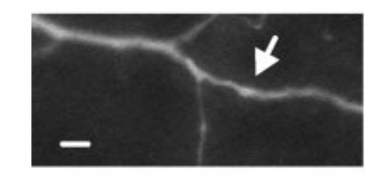

B

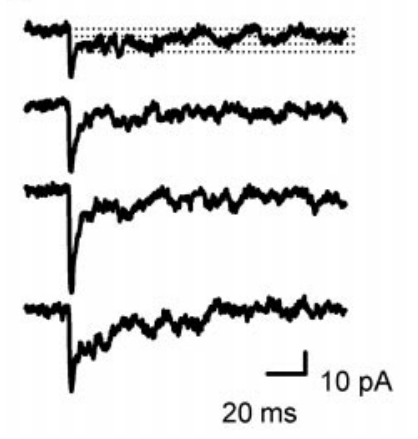

C

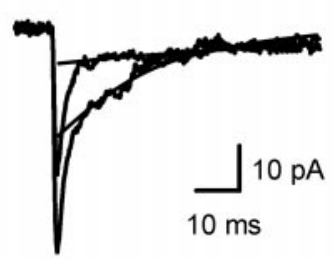

$\mathrm{D}$

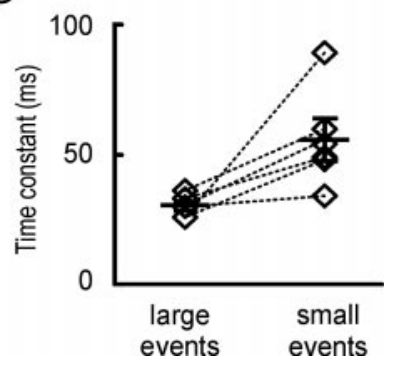

Figure 7. Relationship between the amplitude and the decay time constant of mEPSCs mediated by NMDARs at identified synapses. $A$, Fluorescent image of dendrite. Twelve mEPSCs were observed at a synapse indicated by the arrow. Scale bar, $5 \mu \mathrm{m}$. $B$, Example of mEPSCs that were coincident with MSCTs at an identified synapse. Dotted lines on the top trace show the unitary current amplitude of NMDA receptor channels $(50$ $\mathrm{pS}$ at $-65 \mathrm{mV}) . C$, Superimposed average mEPSCs from six mEPSCs with low amplitude and six mEPSCs with high amplitude fitted to a sum of two exponential components (only slow component fits are shown). The trace averages were selected from records with NMDAR peak responses $50 \%$ above and below the median response. The time constants of slow components were 26 and $89 \mathrm{msec}$ (thin lines). D, Comparison of decay time constant between averages of large and small mEPSCs at six identified synapses on six neurons. Fluo-3 concentration was $0.2 \mathrm{~mm}$.

suggest that a calcium-mediated feedback mechanism takes place during single synaptic events to selectively shape the decay time course of NMDAR-mediated mEPSCs.

To test the possible contribution of calcium-induced calcium release (Emptage et al., 1999) on calcium transients mediated by NMDARs in our recording condition, we tested the effect of ryanodine on the amplitude and time course of MSCTs. We found that ryanodine $(1 \mu \mathrm{M})$ was without effect on MSCT amplitude $(n=9 ; p>0.6)$. In contrast, ryanodine abolished caffeine (10 mM)-induced calcium transients ( $n=4$; data not shown).

Trial-to-trial variability in glutamate release can alter the number of NMDARs activated during mEPSCs (Umemiya et al., 1999). If calcium-mediated acceleration of mEPSC decay kinetics (NMDAR component) is more pronounced for mEPSCs with larger peak amplitudes, it could reduce trial-to-trial variation in calcium influx, because the MSCT amplitude is related to the integral of the NMDAR current (Murphy et al., 1995; Umemiya et al., 1999). To test the contribution of calcium-mediated feedback in regulating MSCT amplitude and variance, we measured the amplitude variability of repeated MSCTs at single synapses (Fig. 8A). Figure $8 B$ shows the spatial and temporal profile of MSCTs that were observed at a putative synapse shown in Figure $8 A$. Figure $8 C$ shows the amplitude distribution of MSCTs at the same synapse measured with $0.5 \mathrm{~mm}$ Fluo-3 in the pipette solution. At this synapse, we observed $40 \mathrm{MSCT}$ s with a mean amplitude of $0.61 \pm 0.03 \Delta F / F$; the coefficient of variation $(\mathrm{CV})$ (SD/mean) was 0.29 . At 22 synapses on 14 cells in which at least 8 MSCTs were observed (number of events per synapse, $17.2 \pm$ 2.2), the mean MSCT amplitude and $\mathrm{CV}$ were $0.55 \pm 0.05 \Delta F / F$

and $0.27 \pm 0.01$, respectively. To test the contribution of the baseline noise to the MSCT variability, the variance of baseline fluorescence for periods without events were measured, and the ratio of the baseline noise (SD) to the mean amplitude of MSCTs was calculated (six synapses on six cells). The average ratio of the SD to the MSCT amplitude was $0.07 \pm 0.01$, indicating that the contribution of the baseline noise was minor $(<3 \%)$ (Mackenzie, 1996). To determine the contribution of calcium-mediated facilitation of mEPSC (NMDAR component) decay on the variability of MSCT amplitude, we used varying amounts of Fluo-3 and found that MSCT variance increased with intracellular calcium buffer concentration (Fig. 8D). With $2 \mathrm{~mm}$ Fluo-3 in the pipette solution, the CV of the MSCT amplitude was $0.37 \pm 0.04$ at 13 synapses on 4 cells (number of events per synapse, $9.8 \pm 1.8$ ) and was significantly larger than that observed with $0.5 \mathrm{~mm}$ Fluo-3 in the pipette solution ( $\mathrm{CV}$ of $0.27 ; p<0.05$ ). The $\mathrm{CV}$ of MSCTs measured at $0.2 \mathrm{~mm}$ Fluo-3 was $0.21 \pm 0.02$ (12 synapses on 5 cells; number of events per synapse, $11.8 \pm 1.9)$ and was smaller than that measured with $0.5 \mathrm{~mm}$ Fluo-3 $(p<0.05)$. We suggest that, in the absence of exogenous calcium buffers, the decay phase of the NMDAR mEPSC is accelerated by calcium entry, leading to a more uniform amount of calcium entry during repeated mEPSCs of varied peak amplitude. It is unlikely that the increased CV for MSCT amplitude attributed to calcium buffer addition was a result of a nonselective increase in mEPSC variance, because the $\mathrm{CV}$ of the initial amplitude of NMDARmediated mEPSCs (before feedback is initiated) was not different from that measured at $1 \mathrm{~mm}$ Fluo-3 $(p>0.25)$; the $\mathrm{CV}$ values were $0.43 \pm 0.05(n=6)$ and $0.51 \pm 0.06(n=6)$ for 0.2 and $1 \mathrm{~mm}$ Fluo-3, respectively. In addition, the peak amplitudes of NMDAR- and AMPAR-mediated mEPSCs were not dependent on the concentration of exogenous calcium buffer (Fig. 1D). Furthermore, the CV for MSCT amplitude obtained in $2 \mathrm{~mm}$ Fluo-3 is similar to that reported for the NMDAR-mediated peak mEPSC amplitude (Umemiya et al., 1999), suggesting that, under conditions in which calcium-mediated feedback is suppressed, MSCT variance is primarily attributed to differences in the number of open receptors.

In younger cultures in which relatively calcium-insensitive NR1/NR2B heteromers are predominantly expressed (Krupp et al., 1996), the variability of MSCT amplitude was larger than that in older cultures (14 synapses on 6 cells; $p<10^{-4}$ ) (Fig. $8 D$ ). In addition, the variability of MSCTs measured with $0.2 \mathrm{~mm}$ Fluo-3 was not significantly different from that with $2 \mathrm{~mm}$ Fluo-3 (6 synapses on 3 cells) in young cultures $(p>0.3)$. The larger MSCT variability for young cultures (compared with old) could be attributed to the lower open probability of NR1/NR2B heteromers than that of NR1/NR2A heteromers (Chen et al., 1999). However, it is also possible that the calcium-mediated acceleration of NMDAR mEPSC decay would tend to reduce MSCT variability associated with NR1/NR2A expression in older cultures.

The increase in the MSCT variability at $2 \mathrm{~mm}$ Fluo-3 was not attributed to an increase of the baseline noise, because the $\mathrm{CV}$ of the baseline ( $\mathrm{CV}$ of $0.05 \pm 0.01 ; n=13$ synapses on 4 cells) was not significantly different from that measured at $0.5 \mathrm{~mm}$ Fluo-3 ( $\mathrm{CV}$ of $0.07 ; p>0.36$ ). In addition, the variability of calcium transients induced by action potentials at $2 \mathrm{~mm}$ Fluo-3 (CV of $0.06 \pm 0.01 ; n=5$ cells) was not different from that observed at $0.5 \mathrm{~mm}$ Fluo-3 ( $\mathrm{CV}$ of $0.05 ; p>0.65$ ). It is also unlikely that the variability of MSCTs was suppressed because of the local saturation of calcium-sensitive dye because we observed a significant 

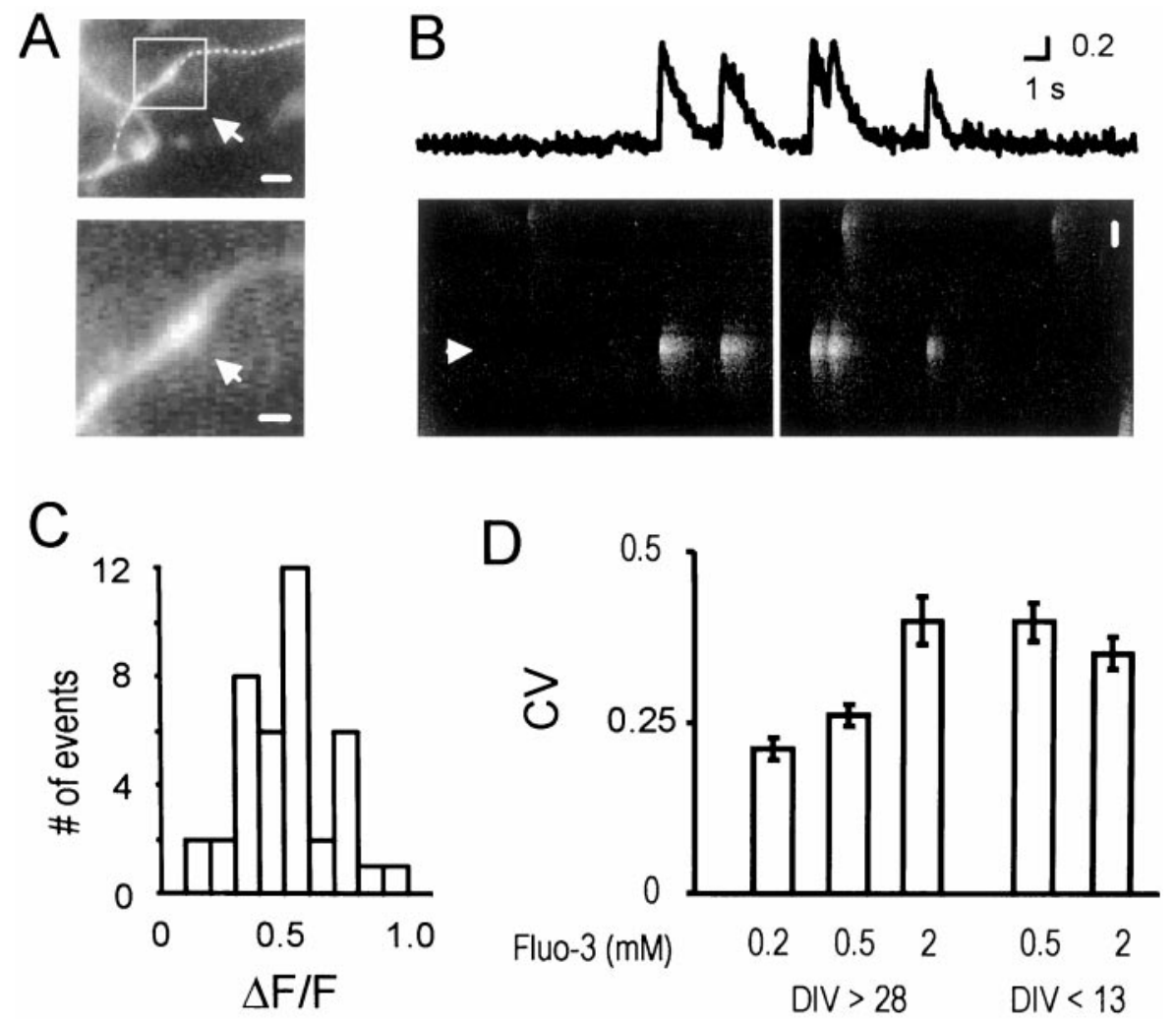

Figure 8. Variability in the amplitude of repeated MSCTs. $A$, At the dendritic site shown (arrow), 40 MSCTs were observed with the mean amplitude of $0.61 \pm 0.03 \Delta F / F(\mathrm{CV}$ of 0.29$)$ over $360 \mathrm{sec}$. The Fluo-3 concentration was $0.5 \mathrm{~mm}$. Scale bars: top, 3 $\mu \mathrm{m}$; bottom, $1 \mu \mathrm{m}$. $B$, Line scan image and time course of repeated MSCTs observed at the site indicated in $A$. Scale bar, $5 \mu \mathrm{m}$. $C$, Amplitude histogram of MSCTs at the site indicated in $A . D, \mathrm{CV}$ values for amplitude of repeated MSCTs were determined in various concentrations of Fluo-3. Error bars represent the SEM. Number of synapses were 12,22 , and 13 for $0.2,0.5$, and $2 \mathrm{~mm}$ Fluo- 3 at $>28$ DIV, respectively, and 14 and 6 for 0.5 and $2 \mathrm{~mm}$ Fluo-3 at $<13$ DIV, respectively. positive correlation between the mean MSCT amplitude and the SD of MSCTs ( $p<0.005 ; f$ test). If the dye saturated during MSCTs, the SD would be relatively smaller for the larger MSCTs. Furthermore, to confirm the linear relationship between the calcium influx and the amplitude of calcium transients, we measured the amplitude of calcium transients induced by voltage-gated calcium channels under voltage clamp (data not shown). We found that the amplitude of calcium transients was proportional to the calcium influx measured from the integral of the charge influx through voltage-gated calcium channels up to $1.27 \Delta F / F$. At all sites tested, the correlation between charge influx and $\Delta F / F$ was linear ( $p<0.002 ; f$ test; $n=4$ neurons; the average $r^{2}$ value was $0.97 \pm 0.006)$. Because the mean plus $3 \mathrm{SD}$ of the MSCT amplitude did not exceed the linear range of the relationship between calcium influx and $\Delta F / F$ at all synapses (up to 1.27 $\Delta F / F)$, we concluded that the variability of MSCTs was not suppressed by our recording system or conditions.

\section{DISCUSSION}

We have found that the decay of the NMDAR component of mEPSCs is facilitated by calcium influx through the channel providing a negative feedback mechanism. It has been shown previously that intracellular calcium negatively modulates NMDAR activity in a variety of ways, including inactivation, acceleration of desensitization, and peak current rundown (McBain and Mayer, 1994). These processes are triggered by sustained and/or repetitive agonist pulses and can be initiated by trains of synaptic stimuli (Rosenmund et al., 1995; Tong et al., 1995). Our results show that a more rapid calcium-dependent process occurs during a single synaptic stimulus, leading to facilitation of the decay of the NMDAR component of mEPSCs. NMDAR calcium-dependent inactivation and acceleration of desensitization are mediated, at least in part, by activation of calcium/calmodulin and the protein phosphatase calcineurin, respectively (Lieberman and Mody, 1994; Tong and Jahr, 1994; Ehlers et al., 1996; Wyszynski et al., 1997; Zhang et al., 1998). Additional protein phosphatases have been shown to decrease NMDAR channel activity (Wang et al., 1994), and activation of the cAMP-dependent protein kinase opposes the action of calcineurin after trains of synaptic stimuli (Raman et al., 1996). Recently, activation of protein kinase $\mathrm{C}$ has been shown to accelerate $\mathrm{Ca}^{2+}$-dependent NMDAR inactivation ( $\mathrm{Lu}$ et al., 2000). Because these processes can occur on a time scale ranging from milliseconds to seconds (Tong et al., 1995; Xia et al., 1998; Zuhlke et al., 1999), it is possible that calcium/calmodulin or activation of protein kinases and/or phosphatases play a role in the calcium-mediated facilitation of the decay of mEPSCs mediated by NMDARs we have observed. Consistent with this proposal, our data indicate that the decay time course of NMDARmediated mEPSCs is sensitive to calcineurin inhibitors or fast calcium chelators (such as the BAPTA analog Fluo-3), similar to that reported previously for $\mathrm{Ca}^{2+}$-dependent inactivation and calcineurin-mediated acceleration of desensitization (Tong and Jahr, 1994; Krupp et al., 1996). Moreover, the fact that strontium does not substitute for calcium suggests similar protein targets as those that mediate calcium-dependent inactivation (Legendre et al., 1993). Perhaps the differential calcium sensitivity of the decay time course we have observed between neuronal NMDARs and heterologously expressed NR1/NR2A in HEK 293 cells could be the result of differences in the basal phosphorylation state. Because calcineurin inhibitors were not completely effective at blocking the calcium-mediated acceleration of mEPSC decay, it is possible that the direct binding of calcium to $\alpha$-actinin (triggering its dissociation from NMDARs) also makes a significant contribution to the inactivation process (Krupp et al., 1999). 
Studies indicate that NMDAR subtypes may be differentially sensitive to regulation by $\left[\mathrm{Ca}^{2+}\right]_{\mathrm{I}}$; therefore, we have focused on NMDARs at mature synapses expressing both AMPARs and NMDARs, including high levels of the NR2A subunit, which is more sensitive to $\mathrm{Ca}^{2+}$-dependent inactivation than NR2B (Monyer et al., 1994; Zhong et al., 1995; Krupp et al., 1996; Li et al., 1998; Harris, 1999; Tovar and Westbrook, 1999). In addition to the subunit composition, the spine structure changes during the course of development (Harris, 1999). It is possible that the spine structure has a significant impact on the amplitude and the time course of calcium transients and, therefore, modulates the calcium-dependent facilitation of mEPSC decay time course mediated by NMDARs (Muller and Connor, 1991; Koch and Zador, 1993; Malinow et al., 1994; Magee and Johnston 1997; Harris, 1999; Kovalchuk et al., 2000; Murthy et al., 2000). Interestingly, younger neurons that have less developed spines and a lower proportion of NR2A (vs NR2B) expression do not show the calcium-mediated facilitation of the mEPSC decay time course mediated by NMDAR. In the case of the receptor modulation by phosphorylation, the situation is complicated because both calcium-activated protein phosphatases and kinases are present. The amplitude and time course of calcium transients, the affinity of enzymes or cofactors for calcium, and the relative localization of NMDARs may determine whether these calcium-dependent processes enhance or suppress NMDAR activity. Under the conditions we have used, it is possible that calcium influx into spines (through NMDARs) during miniature synaptic events results in a greater activation of phosphatases than kinases. Protein phosphatase activation could then lead to a facilitation of the NMDAR mEPSC decay time course. Alternatively, miniature synaptic activity might lead to activation of select protein kinases, such as protein kinase $\mathrm{C}$, that are linked to an increase in calcium-dependent inactivation (Lu et al., 2000). At extrasynaptic receptors such as those expressed in heterologous cells (HEK 293), differences in calcium dynamics compared with spines may be responsible for the lack of exogenous calcium buffer effects on the facilitation of the decay time course of NMDAR currents. Alternatively, differences in the glutamate application kinetics between the HEK 293 cell experiments and synaptic release may have contributed to the apparent lack of an effect of the added calcium buffers on decay kinetics.

The calcium-mediated facilitation of the NMDAR component of the mEPSC decay time course we have observed provides a negative feedback mechanism to keep the amplitude of the synaptic calcium transient at a rather constant level. We predict that the feedback mechanism should reduce trial-to-trial variability in the amplitude of miniature synaptic calcium transients attributed to NMDARs. Consistent with this prediction, we observe that (1) fast exogenous buffers (that block the feedback mechanism) increase trial-to-trial variability in NMDAR calcium transients, and (2) young neurons that lack the feedback mechanism have larger trial-to-trial variability in NMDAR calcium transients. The mechanisms of trial-to-trial variability in NMDAR-mediated currents are important, because they provide clues as to how the receptor can be regulated. In addition to the feedback mechanism we describe, at least two other factors are likely to contribute significantly to control of MSCT trial-to-trial amplitude variability: (1) the random stochastic properties of the opening of a small number of receptors with low open probability (Bekkers and Stevens, 1989; Faber et al., 1992; Silver et al., 1992; Murphy et al., 1995; Forti et al., 1997); (2) variation in transmitter release onto receptors that are not saturated with agonist (Umemiya et al.,
1999; McAllister and Stevens, 2000). The dependence of the feedback mechanism we have described on the amount of local calcium entry would suggest that conditions resulting in robust calcium entry at single synapses would be most likely to activate the mechanism. Physiologically, these conditions will include presynaptic stimulation paired with strong postsynaptic depolarization to remove $\mathrm{Mg}^{2+}$ block and to maximize the amount of calcium entry through each receptor and into each synapse (Yuste and Denk, 1995; Koester and Sakmann, 1998; Schiller et al., 1998; Yuste et al., 1999).

In conclusion, we argue that the size of the calcium transients mediated by NMDARs is regulated by a negative feedback mechanism via calcium influx through the receptor. Therefore, we expect that the amplitude of NMDAR-mediated calcium transients would be controlled by parameters that affect the calcium concentration, such as synapse volume, rates of calcium diffusion and clearance, and calcium-induced calcium release. Because these parameters may vary between synapses, it is likely that each synapse has a unique ability for the activity-dependent synaptic modulation mediated by NMDARs.

\section{REFERENCES}

Bekkers JM, Stevens CF (1989) NMDA and non-NMDA receptors are co-localized at individual excitatory synapses in cultured rat hippocampus. Nature 341:230-233.

Bekkers JM, Stevens CF (1996) Cable properties of cultured hippocampal neurons determined from sucrose-evoked miniature EPSCs. J Neurophysiol 75:1250-1255.

Carmignoto G, Vicini S (1992) Activity-dependent decrease in NMDA receptor responses during development of the visual cortex. Science 258:1007-1011.

Chen C, Okayama H (1987) High-efficiency transformation of mammalian cells by plasmid DNA. Mol Cell Biol 7:2745-2752.

Chen N, Luo T, Raymond LA (1999) Subtype-dependence of NMDA receptor channel open probability. J Neurosci 19:6844-6854.

Collingridge GL, Bliss TV (1995) Memories of NMDA receptors and LTP. Trends Neurosci 18:54-56.

Ehlers MD, Zhang S, Bernhadt JP, Huganir RL (1996) Inactivation of NMDA receptors by direct interaction of calmodulin with the NR1 subunit. Cell 84:745-755.

Emptage N, Bliss TV, Fine A (1999) Single synaptic events evoke NMDA receptor-mediated release of calcium from internal stores in hippocampal dendritic spines. Neuron 22:115-124.

Faber DS, Young WS, Legendre P, Korn H (1992) Intrinsic quantal variability due to stochastic properties of receptor-transmitter interactions. Science 258:1494-1498.

Forti L, Bossi M, Bergamaschi A, Villa A, Malgaroli A (1997) Loosepatch recordings of single quanta at individual hippocampal synapses. Nature 388:874-878.

Harris KM (1999) Structure, development, and plasticity of dendritic spines. Curr Opin Neurobiol 9:343-348.

Helmchen F, Imoto K, Sakmann B (1996) $\mathrm{Ca}^{2+}$ buffering and action potential-evoked $\mathrm{Ca}^{2+}$ signaling in dendrites of pyramidal neurons. Biophys J 70:1069-1081.

Hestrin S (1992) Developmental regulation of NMDA receptormediated synaptic currents at a central synapse. Nature 357:686-689.

Hollmann M, Heinemann S (1994) Cloned glutamate receptors. Annu Rev Neurosci 17:31-108.

Imredy JP, Yue DT (1992) Submicroscopic $\mathrm{Ca}^{2+}$ diffusion mediates inhibitory coupling between individual $\mathrm{Ca}^{2+}$ channels. Neuron 9:197-207.

Jahr CE, Stevens CF (1993) Calcium permeability of the $N$-methyl-Daspartate receptor channel in hippocampal neurons in culture. Proc Natl Acad Sci USA 90:11573-11577.

Jones MV, Westbrook GL (1996) The impact of receptor desensitization on fast synaptic transmission. Trends Neurosci 19:96-101.

Koch C, Zador A (1993) The function of dendritic spines: devices subserving biochemical rather than electrical compartmentalization. J Neurosci 13:413-422.

Koester HJ, Sakmann B (1998) Calcium dynamics in single spines during coincident pre- and postsynaptic activity depend on relative timing of back-propagating action potentials and subthreshold excitatory postsynaptic potentials. Proc Natl Acad Sci USA 95:9596-9601.

Kovalchuk Y, Eilers J, Lisman J, Konnerth A (2000) NMDA receptormediated subthreshold $\mathrm{Ca}^{2+}$ signals in spines of hippocampal neurons. J Neurosci 20:1791-1799.

Krupp JJ, Vissel B, Heinemann SF, Westbrook GL (1996) Calcium- 
dependent inactivation of recombinant $N$-methyl-D-aspartate receptors is NR2 subunit specific. Mol Pharmacol 50:1680-1688.

Krupp JJ, Vissel B, Thomas CG, Heinemann SF, Westbrook GL (1999) Interactions of calmodulin and $\alpha$-actinin with the NR1 subunit modulate $\mathrm{Ca}^{2+}$-dependent inactivation of NMDA receptors. J Neurosci 19:1165-1178.

Lattanzio Jr FA, Bartschat DK (1991) The effect of pH on rate constants, ion selectivity and thermodynamic properties of fluorescent calcium and magnesium indicators. Biochem Biophys Res Commun 177:184-191.

Legendre P, Rosenmund C, Westbrook GL (1993) Inactivation of NMDA channels in cultured hippocampal neurons by intracellular calcium. J Neurosci 13:674-684.

Li JH, Wang YH, Wolfe BB, Krueger KE, Corsi L, Stocca G, Vicini S (1998) Developmental changes in localization of NMDA receptor subunits in primary cultures of cortical neurons. Eur J Neurosci 10:1704-1715.

Lieberman DN, Mody I (1994) Regulation of NMDA channel function by endogenous $\mathrm{Ca}(2+)$-dependent phosphatase. Nature 369:235-239.

Lu WY, Jackson MF, Bai D, Orser BA, MacDonald JF (2000) In CA1 pyramidal neurons of the hippocampus protein kinase $\mathrm{C}$ regulates calcium-dependent inactivation of NMDA receptors. J Neurosci 20: 4452-4461.

Mackenzie PJ, Umemiya M, Murphy TH (1996) $\mathrm{Ca}^{2+}$ imaging of CNS axons in culture indicates reliable coupling between single action potentials and distal functional release sites. Neuron 16:783-795.

Mackenzie PJ, Kenner GS, Prange O, Shayan H, Umemiya M, Murphy TH (1999) Ultrastructural correlates of quantal synaptic function at single CNS synapses. J Neurosci 19:RC13.

Magee JC, Johnston D (1997) A synaptically controlled, associative signal for Hebbian plasticity in hippocampal neurons. Science 275:209-213.

Malenka RC, Nicoll RA (1999) Long-term potentiation: a decade of progress? Science 285:1870-1874.

Malinow R, Otmakhov N, Blum KI, Lisman J (1994) Visualizing hippocampal synaptic function by optical detection of $\mathrm{Ca}^{2+}$ entry through the $N$-methyl-D-aspartate channel. Proc Natl Acad Sci USA 91:8170-8174.

Mayer ML, MacDermott AB, Westbrook GL, Smith SJ, Barker JL (1987) Agonist- and voltage-gated calcium entry in cultured mouse spinal cord neurons under voltage clamp measured using arsenazo III. J Neurosci 7:3230-3244

McAllister AK, Stevens CF (2000) Nonsaturation of AMPA and NMDA receptors at hippocampal synapses. Proc Natl Acad Sci USA 97:6173-6178.

McBain CJ, Mayer ML (1994) N-methyl-D-aspartic acid receptor structure and function. Physiol Rev 74:723-760.

Monyer H, Burnashev N, Laurie DJ, Sakmann B, Seeburg PH (1994) Developmental and regional expression in the rat brain and functional properties of four NMDA receptors. Neuron 12:529-540.

Muller W, Connor JA (1991) Dendritic spines as individual neuronal compartments for synaptic $\mathrm{Ca}^{2+}$ responses. Nature 354:73-76.

Murphy TH, Baraban JM, Wier WG, Blatter LA (1994) Visualization of quantal synaptic transmission by dendritic calcium imaging. Science 263:529-532.

Murphy TH, Baraban JM, Wier WG (1995) Mapping miniature synaptic currents to single synapses using calcium imaging reveals heterogeneity in postsynaptic output. Neuron 15:159-168.

Murthy VN, Sejnowski TJ, Stevens CF (2000) Dynamics of dendritic calcium transients evoked by quantal release at excitatory hippocampal synapses. Proc Natl Acad Sci USA 97:901-906.

Naraghi M, Neher E (1997) Linearized buffered $\mathrm{Ca}^{2+}$ diffusion in microdomains and its implications for calculation of $\left[\mathrm{Ca}^{2+}\right]$ at the mouth of a calcium channel. J Neurosci 17:6961-6973.

Nicoll RA, Malenka RC (1995) Contrasting properties of two forms of long-term potentiation in the hippocampus. Nature 377:115-118.

Raman IM, Tong G, Jahr CE (1996) $\beta$-adrenergic regulation of synap- tic NMDA receptors by cAMP-dependent protein kinase. Neuron $16: 415-421$.

Rosenmund C, Westbrook GL (1993) Calcium-induced actin depolymerization reduces NMDA channel activity. Neuron 10:805-814.

Rosenmund C, Feltz A, Westbrook GL (1995) Calcium-dependent inactivation of synaptic NMDA receptors in hippocampal neurons. J Neurophysiol 73:427-430.

Schiller J, Schiller Y, Clapham D (1998) NMDA receptors amplify calcium influx into dendritic spines during associative pre- and postsynaptic activation. Nat Neurosci 1:114-118.

Sheng M, Cummings J, Roldan LA, Jan YN, Jan LY (1994) Changing subunit composition of heteromeric NMDA receptors during development of rat cortex. Nature 368:144-147.

Silver RA, Traynelis SF, Cull Candy SG (1992) Rapid-time course miniature and evoked excitatory currents at cerebellar synapses in situ. Nature 355:163-166.

Smith GD, Wagner J, Keizer J (1996) Validity of the rapid buffering approximation near a point source of calcium ions. Biophys $\mathbf{J}$ 70:2527-2539.

Sugihara H, Moriyoshi K, Ishii T, Masu M, Nakanishi S (1992) Structures and properties of seven isoforms of the NMDA receptor generated by alternative splicing. Biochem Biophys Res Commun $185: 826-832$

Tong G, Jahr CE (1994) Regulation of glycine-insensitive desensitization of the NMDA receptor in outside-out patches. J Neurophysiol 72:754-761.

Tong G, Shepherd D, Jahr CE (1995) Synaptic desensitization of NMDA receptors by calcineurin. Science 267:1510-1512.

Tovar KR, Westbrook GL (1999) The incorporation of NMDA receptors with a distinct subunit composition at nascent hippocampal synapses in vitro. J Neurosci 19:4180-4188.

Umemiya M, Senda M, Murphy TH (1999) Behavior of NMDA and AMPA receptor mediated miniature EPSCs at synapses identified by calcium imaging. J Physiol (Lond) 521:113-122.

Vyklick'y LJ, Benveniste M, Mayer ML (1990) Modulation of $N$-methylD-aspartic acid receptor desensitization by glycine in mouse cultured hippocampal neurones. J Physiol (Lond) 428:313-331.

Wang LY, Orser BA, Brautigan DL, MacDonald JF (1994) Regulation of NMDA receptors in cultured hippocampal neurons by protein phosphatases 1 and 2A. Nature 369:230-232.

Wang S, Prange O, Murphy TH (1999) Amplification of calcium signals at dendritic spines provides a method for CNS quantal analysis. Can J Physiol Pharmacol 77:651-659.

Wyszynski M, Lin J, Rao A, Nigh E, Beggs AH, Craig AM, Sheng M (1997) Competitive binding of $\alpha$-actinin and calmodulin to the NMDA receptor. Nature 385:439-442.

Xia XM, Fakler B, Rivard A, Wayman G, Johnson-Pais T, Keen JE, Ishii T, Hirschberg B, Bond CT, Lutsenko S, Maylie J, Adelman JP (1998) Mechanism of calcium gating in small-conductance calcium-activated potassium channels. Nature 395:503-507.

Yuste R, Denk W (1995) Dendritic spines as basic functional units of neuronal integration. Nature 375:682-684.

Yuste R, Majewska A, Cash SS, Denk W (1999) Mechanisms of calcium influx into hippocampal spines: heterogeneity among spines, coincidence detection by NMDA receptors, and optical quantal analysis. J Neurosci 19:1976-1987.

Zhang S, Ehlers MD, Bernhardt JP, Su CT, Huganir RL (1998) Calmodulin mediates calcium-dependent inactivation of $N$-methyl-Daspartate receptors. Neuron 21:443-453.

Zhong J, Russell SL, Pritchett DB, Molinoff PB, Williams K (1994) Expression of mRNAs encoding subunits of the $N$-methyl-D-aspartate receptor in cultured cortical neurons. Mol Pharmacol 45:846-853.

Zhong J, Carrozza DP, Williams K, Pritchett DB, Molinoff PB (1995) Expression of mRNAs encoding subunits of the NMDA receptor in developing rat brain. J Neurochem 64:531-539.

Zuhlke RD, Pitt GS, Deisseroth K, Tsien RW, Reuter H (1999) Calmodulin supports both inactivation and facilitation of L-type calcium channels. Nature 399:159-162. 